This document may be reprinted and distributed for non-commercial and educational purposes only, and not for resale. No resale use may be made of material on this web site at any time. All other rights reserved.

Made available courtesy of the National Recreation \& Park Association: http://www.nrpa.org/

\title{
Articles
}

\section{Adolescent Girls' Involvement in Disability Sport: A Comparison of Social Support Mechanisms}

\author{
Denise M. Anderson, Ph.D. and Angela Wozencroft, ABD \\ Clemson University
}

Leandra A. Bedini, Ph.D., CTRS, LRT

University of North Carolina at Greensboro

\begin{abstract}
Authors
Denise M. Anderson is an Assistant Professor and Co-Director of Graduate Studies in the Department of Parks, Recreation, and Tourism Management at Clemson University. Angela Wozencroft is a doctoral student in therapeutic recreation in the Department of Parks, Recreation, and Tourism Management at Clemson University. Leandra A. Bedini is a Professor and Director of Graduate Study in the Department of Recreation, Tourism, and Hospitality Management at The University of North Carolina at Greensboro.
\end{abstract}

\section{Abstract}

\begin{abstract}
Women and girls with disabilities are historically disenfranchised from physical recreation due to the "double whammy" of being female and having a disability. The literature suggests that challenges to participation likely include lack of social support for girls with disabilities to participate in sport. Therefore, the purpose of the study was to examine differences in social support received by girls with disabilities who did and did not participate in organized wheelchair sport programs. In addition, the relationship between social support and outcomes tied to wheelchair sport participation were investigated. Data were collected using semi-structured interviews and analyzed using constant comparison techniques. Utilizing a model of social support as a framework, the findings illustrate multiple differences in social support mechanisms for girls who are and who are not involved in wheelchair sport programs.
\end{abstract}

KEYWORDS: Disability, Females, Social Support, Sport

\section{Introduction}

Herein lies the newest and most accessible pathway out of the disability ghetto. To take on and, in fact, excel in a physical challenge which, by definition and custom, you should not, this is the ultimate high! The dwarf basketball player, the blind runner, the amputee skier, or the cyclist with cerebral palsy, these are the able disabled. Wyeth, 1989, p. 6)

Address correspondence to: Denise Anderson, Clemson University, 263 Lehotsky, Box 340735, Clemson, South Carolina29634 or dander2@clemson.edu.

Authors note: The current research is a representation of data collected in a study of leisure access issues for girls with disabilities. 
Although Wyeth's quote is dated, many people with disabilities are still faced with innumerable hurdles to escaping the "disability ghetto." In particular, women and girls with disabilities have been historically disenfranchised from physical recreation due to the "double whammy" of being female and having a disability. Membership in two minority groups more than doubles the chances of being compromised in the pursuit of recreation opportunities and resources (Decgan, 1985). In addition to fewer opportunities, societal perceptions of weakness as well as barriers tied to fear for safety, poor self-esteem and body image, and numerous other gender and disability-specific obstacles all lend themselves to lower participation levels (e.g., Ashton-Shaeffer, Gibson, Hold \& Willming, 2001; French \& Hainsworth, 2001). Overcoming the barriers from membership in one group does not automatically dispel the difficulties tied to the other group. For instance, Title IX of the Educational Amendments Act of 1972 assisted in the development of more female sports opportunities, yet did nothing to dispel constraints related to sport participation for girls with disabilities. As recently as 2003, Jones reported that girls and women with disabilities are still overlooked in recreation programming for a variety of reasons including low levels of social support.

The benefits of engaging in sport and physical activity are well-documented. These include increased fitness and health; a longer life span; greater mental, social, and spiritual well- being; increased self-estcem; socialization; and decreased stress (e.g., Kristen, Patriksson, \& Fridlund, 2002, 2003; Martin, 2006). However, while participation by women and girls in sport has increased in the United States as a result of Title IX, gender stereotypes, lack of funding, lack of appropriate programming, lack of role models, and other issues still constrain participation (e.g., Anderson, Bedini, \& Moreland, 2005; Appleton et al., 1994; French \& Hainsworth, 2001; Kolkka \& Williams, 1997). Participation in sport for girls with disabilities in particular, however, has been compromised greatly by a lack of social support. For example, Blinde and McAllister (1999) found that women with physical disabilities expressed that societal expectations of their "place" (or lack thereof) in sport and physical activity arenas tended to negatively affect their participation. The socialization of women into gender appropriate roles has negative ramifications for both girls and women with disabilities. Thus, Henderson, Bedini, and Bialeschki (1993) have asserted that a lack of support for expanding the roles of women (e.g., as an athlete) through therapeutic recreation, rather than simply restoring their abilities to engage in "appropriate" female roles, does them a disservice.

Social obstacles to continued participation in sport also persist. Children with disabilities are at higher risk to withdraw from physical activity due to issues such as low self-esteem and socialization (Dunn, 2000). In addition, children with disabilities are often socialized into the role of spectator early in life by family and friends. Overprotection of children with disabilities by parents and other adults can also be a barrier to participation (Kristen et al., 2003; Taub \& Greer, 2000). For these reasons, friends and family, through reinforcement and modeling of behaviors that they deem important, can serve as facilitators or barriers to participation (DePauw \& Gavron, 2005). Researchers such as Brittain (2004), DePauw (1999), Kristen, Patrickson, and Fridlund (2003) have also found that the presence or absence of social support has a significant impact on the participation of girls and women with disabilities in organized sports programs. 
There is, however, potential for organized sports programs for youth with disabilities to provide an environment of social support that is important to the development of self-esteem, identity, and a sense of empowerment. In fact, Doubt and McColl (2003) have suggested that competitive activities in particular have high "value" among adolescents, thus they have potential to play many roles in the lives of adolescent girls with disabilities if support is available. Therefore, the purpose of this study was to examine differences in experiences of social support between girls who participate in organized versus non-organized sports and to understand the organizational factors that contributed to or hindered perceptions of social support. The paper covers a review of literature relevant to an examination of disability sport as well as a description of the conceptual foundation of social support. This is followed by a description of data collection and analyses techniques and the findings of the study. The findings are categorized in five themes related to social support and outcomes from formal and informal sport participation. Finally, a discussion tying the results back to the conceptual framework of the study is presented.

\section{Review of Relevant Literature}

Much of the research to date has focused on women with disabilities rather than girls. While this study focuses on the perceptions of adolescent girls, the background literature is centered on previous work that examines the role of sport in the lives of women. Recognizing that there are likely differences in the experiences for girls and women, the authors nonetheless felt that an examination of the previous literature on women is relevant and applicable to the current study focused on girls. While the age of the participant may be different, one would still be able to relate gender issues to both groups.

\section{Disability Sport}

Disabilities are often defined as individual differences in appearance, structure, function, and performance that society sees as undesirable (Pensgaard \& Sorensen, 2002). Goffman (1963) defined stigma as "the situation of the individual who is disqualified from full social acceptance" (p. 5). This "disqualification" has been particularly evident in sport where a disabled body often does not meet the guidelines of the "ideal sporting body" (Hardin, 2003). After all, as reported by Benson (1997), "The body is...the medium through which messages about identity are transmitted" (p. 123); thus a disabled body would not convey the image of an "athlete." Historically the "ideal sporting body" was one reflected in the physique of an able-bodied male (DePauw \& Gavron, 2005). The concept of the athletic body and its attributes is one of strength, skill, endurance, and speed (Hargreaves, 1987). The idea of a strong body is central to the notion of sport. The association of the female body as weak combined with the notion of a disabled body as disempowered would suggest that a girl or woman with a disability can not and should not participate in sport, a social institution that is available to those with power, both physical and political.

However, in recognition of the power that sport participation can produce, many researchers would argue that sport is an ideal context for resistance to gendered stereotypes, especially in light of the fact that, unlike physical activity, at the heart of 
most sport is competition and therefore it is characterized by social interaction (Ashton-Shacffer, Gibson, Autry, and Hanson, 2001; Guthric \& Castelnuovo, 2001; Theberge, 1987, 1991). In fact, Ashton-Shaeffer et al. (2001), in an examination of adults who participated in a wheelchair sport camp, found that participation in sport did allow for resistance as well as empowerment. As Henderson et al. (1993) stated, both people with and without disabilities need opportunities to challenge socialization and create new opportunities for themselves; sport is one arena where this can occur. In addition, Ashton-Shaeffer, Gibson, Holt, and Willming (2001), in an examination of women who were members of the national wheelchair basketball team, found that the women's experiences had given them the opportunity for resistance to their disability and to society's perceptions of disability. Their experiences had empowered them to recognize their bodies as instruments of power in challenging preconceived notions of the abilities of people with disabilities.

Disability sport is sport that has been adapted from its original context to take into consideration the modifications dictated by the disability (DePauw \& Gavron, 2005). In addition, there are different levels of participation categorization based on type of disability and level of functional ability that allow for play on a more "even" playing field (Stein \& Pacioret, 1994). Disability sport has been identified as a forum where stereotypes about people with disabilities can be altered, particularly perceptions of competence (Hedrick, 1986). However, the primary goal of wheelchair sports is not to normalize, but to liberate people with disabilities (Ashton-Shaeffer, et al., 2001). In general, most people with disabilities enjoy sports for the same reasons as able-bodied participants (Page et al., 2001).

Wheelchair sports in particular can provide an avenue to accent abilities and minimize disabilities (Martin, 1999). A shift in the 1960s from a medicalized (rehabilitation) model to a social model (e.g., recreation and sport) of recreation participation facilitated the growth in wheelchair sports (Hargreaves, 2000; James, 1998; Simeonsson, Carlson, Huntington, McMiller, \& Brent, 2001). However, growth has been difficult in wheelchair sports for girls and women.

Policy is beginning to address the specific issue of low female participation in disability sport. For example,

The Brighton Declaration on Women and Sport (1994) emphasized that the equal opportunity to participate in sport whether for the purpose of leisure and recreation, health promotion, or high performance, is the right of every woman, regardless of race, color, language, religion, creed, sexual orientation, age, marital status, disability, political belief or affiliation, national or social origin. (DePauw \& Gavron, 2005, p. 266).

This Declaration was likely made in response to research such as the survey of women with disabilities that was conducted in 1988 (Fitness Canada, n.d.). The study found that levels of physical activity were insufficient despite the fact that participation was at least somewhat to very important to most respondents and that they preferred organized noncompetitive recreation or competitive activities (to non organized). Although some progress has been made since the Declaration, many girls and women with disabilities still lack the opportunity to participate in sport (Jones, 2003). 


\section{Socialization and Social Supports}

Rosenfeld, Richman, and Hardy (1989) defined social support as, "an exchange of resources between at least two individuals perceived by the provider or the recipient to be intended to enhance the well-being of the recipient" (p. 23). Pines and Aronson (1988) stated that a social support system is made up of people who provide "emotional sustenance, assistance, and resources in times of need, who provide feedback, and who share standards and values" (p. 160). Social support has been linked to decreases in psychological distress in times of stress (DuBois, Felner, Brand, Adan, \& Evans, 1992), as well as physiological health (Uchino, Cacioppo, \& Kiecolt-Glaser, 1996).

As mentioned earlier, by definition sport is typically not a solitary activity and therefore, there is a socialization process inherent in introducing participation to both people with and without disabilities. This socialization process has been identified by Kenyon and McPherson (1981) through a social learning model which suggests that wheelchair athletes would likely be socialized into sport through "Significant others (socializing agents) who exert influence within social situations (socializing agencies) upon role learners (actors or role aspirants) who are characterized by a wide variety of relevant personal attributes" (p. 218).

It is logical that it is the interplay between the three elements of significant others, social situations, and personal attributes that influences participation rates by people with disabilities. While social situations (e.g., school settings, community recreation centers) and personal attributes (e.g., onset of disability, severity of disability) both play strong roles in sport participation, the focus of this study was on the significant others that influenced (positively or negatively) girls with disabilities participation in sport through the social support that they provided.

Socializing agents are typically a child's family, peers, and friends. The degree of support (or lack of support) that is provided by each group is crucial to the socialization process (Doubt \& McColl, 2003). Williams (1994) identified a number of studies that examined the relative importance of different social groups to disability sport participation. For instance, in a study of people with cerebral palsy, Whidden (1986) found that family was the most important social agent to participation while Sherrill and Rainbolt (1986), also examining people with cerebral palsy, identified peers, friends, and spouses as the most important. Hedrick, Morse, and Figoni (1988), looking at elite wheelchair athletes, found that other athletes and magazines (e.g., Sports in Spokes) were the strongest socializers for participation. More recently, Ruddell and Shinew (2006) found that elite female wheelchair basketball players were typically influenced by multiple agents including coaches and players with disabilities, therapists, and wheelchair sport camps. In all cases, schools were seen as having very little to no influence over participation (Ruddell \& Shinew, 2006). In addition, the importance of social agents was often dictated by type of disability, age of participant, and other relative demographic factors. It is important to note that the socialization process, and thus the role of social support, will be different for athletes with disabilities in comparison to those without disabilities (Williams, 1994).

Martin and Mushett (1996), in an examination of athletes with disabilities, found that parents, friends, and coaches were the most frequent providers of support. Friends, mothers, and coaches provided the greatest amount of listening support while friends provided shared social reality support. Mothers, friends, and fathers, in that order, pro- 
vided emotional support. It is important to note that listening, shared social reality, and emotional support do not require any specific knowledge of a particular sport. Technical appreciation and technical support were primarily provided by coaches although parents and friends were also providers. Unlike parents of able-bodied athletes, these parents provided support in all areas, including those that were sport specific (e.g., assisting with practice), likely because the athletes were so dependent on their families for functional and emotional support and lacked a great deal of support outside of their families. Interestingly, mothers consistently "out supported" fathers, perhaps because a greater percentage of the fathers worked full-time, because the mothers were more receptive to other emotional needs, mothers were required to stay home with a child with a disability, or because the mothers had greater knowledge of socially skilled responses. Overall, the athletes who received strong listening support and were challenged both emotionally and technically expressed greater efficacy in ability to train well enough to reach potential (Martin \& Mushett, 1996).

King et al. (2003) identified a number of factors related to social supports that play a role in participation rates and the reduction of stigma. A number are directly tied to the presence of supportive relationships for both the child and the parents and a supportive home environment (physical, mental, social well-being of parents). In addition, child factors such as the child's emotional, behavioral, and social functioning can also influence the impact of social support and how they are socialized into sport (King et al.).

For children, parental support is highly important to success in children's participation in disability sports as parents can influence not only participation, but also competence, motivation and satisfaction levels (Kristen, et al., 2003; Martin, 2006). People with disabilities can be stigmatized and in a disadvantaged social position, yet family support can reduce social isolation, exploitative attitudes and hostile dependence (Tam, 1998). Parental influence on participation and performance is high yet so is the emotional, financial and time investment (Collins \& Barber, 2005). Yet, girls with disabilities often do not enjoy the same support as boys with disabilities. In a study of children with disabilities, Appleton et al. (1994) found that girls perceived lower support from parents perhaps due to lower self-esteem and the perception that they did not "deserve" support. This illustrates the fact that the reactions of peers, lack of role models and overprotective parents can also put up barriers to participation (Doubt \& McColl, 2003; King, Shultz, Stecl, Gilpin, \& Cathers, 1993).

Pcers can also either help or hinder participation (Hutzler, Fliess, Chacham, \& Van den Auweele, 2002). On one hand, teasing or bullying of the child with a disability will likely not encourage participation. On the other hand, if peers are willing to provide help or peers promote participation through encouragement the child is more likely to participate (Hutzler, et al.). In fact, the support of peers can be highly valued as competence in sport can be linked to social status, popularity, and peer acceptance; participation with friends is often a primary motivation for participation in disability sports (Martin, 2006)

It is evident that family, peers, and friends can play an important role in the facilitation of involvement of youth in wheelchair sports. One would assume that the implications of social support in the lives of girls with disabilities would reach far beyond sport participation. For instance, Pines and Aronson (1988) argued that social 
support can be not only comforting but also protective and can help people maintain both psychological and physical well-being. Therefore, a greater understanding of the relationship between social support and sport participation would be instrumental to advancing wheelchair sport opportunities for girls.

Few studies on youth with disabilities have been conducted from the children's point of view (Kristen, Patriksson, \& Fridlund, 2002). Certainly there is a dearth of literature examining the critical role of social support in the lives of children with disabilities, and specifically girls, particularly within the context of disability sport. Researchers are quite aware of the benefits of physically active recreation ranging from increased physical health to benefits to mental health and reductions in stress. However, girls with disabilities face unique barriers to participation that an examination of social support mechanisms may help explain and ultimately alleviate. Due to the lack of research on this population, there are many unanswered questions regarding how to better introduce and retain girls with physical disabilities to organized physical activity, particularly sport. Therefore, the purpose of the study was to examine differences in social support received by girls with disabilities who did and did not participate in organized sport programs and the relationship between social support and outcomes tied to wheelchair sport participation.

\section{Conceptual Framework}

Pines, Aronson, and Kafry (1981) outlined a model of social support that encompasses six types of support. The first, listening support, is the perception that others genuinely care about what a person has to say and will listen non-judgmentally. The second is shared social reality support which is the belief that others share your understanding of the world; this knowledge validates the recipient's feelings. The third type is emotional support which is based on the idea that others care about you and are "on your side." The fourth is emotional challenge support which encompasses the perceptions that others care about you while also facilitating personal growth or development. Technical appreciation support is the perception that others appreciate and support your efforts and accomplishments in a specific setting (e.g., sport). Finally, technical challenge support is similar to emotional challenge, and encourages the individual to do better or achieve more in a specific setting (e.g., sport) (Pines \& Aronson, 1988). Previous research has examined the role of support agents such as family members and peers in the lives of people with disabilities (e.g., Doubt \& McColl, 2003; Ruddell \& Shinew, 2006 ). We were interested in determining if this specific model of social support could be applied to experiences held by girls with disabilities to explain differences in outcomes for participants and non-participants in disability sport. It is recognized that no one person can provide all necessary forms of social support. Different people are needed to fulfill different functions. It is anticipated that participation in organized sport will introduce participants to a variety of people, thus increasing the chances for a variety of types of support. This study proposed to examine whether organized sport does provide more social support mechanisms for girls with physical disabilities and the related benefits of social support.

Thus, the following research questions were investigated for this study: a) What physically active recreation activities do adolescent girls with physical disabilities participate in? b) What social support mechanisms are in place for girls' with disabilities 
introduction to and participation in formal and informal recreation participation? c) How do outcomes by type of participation differ? and d) How are these outcomes influenced by social support?

\section{Participant Recruitment}

\section{Method}

The participants were girls between the ages of 10 and 18 who had only a physical disability and lived in North Carolina, South Carolina, or Georgia. Girls who could participate in a verbal interview were recruited irrespective of activity levels (formal versus informal). Purposive sampling techniques were employed in order to recruit girls who fit specific criteria, in this case presence of a physical disability with the cognitive ability to participate in an interview. Initial participants were recruited through advertisements and word of mouth at churches, recreation centers, schools, and through disabled sports and recreation organizations. The researchers then employed "snowball sampling" whereby once a participant was identified and interviewed, the researchers asked her (and/or her family) to suggest additional girls with disabilities who met the criteria and might be willing to be interviewed (Patton, 1990). Depending on the appropriateness of the recommended participant, she was contacted to participate in the study and subsequently asked for additional contacts. Thus, the selection of participants "snowballed" from the initial contacts.

\section{Data Collection/Procedures}

Face to face semi-structured interviews were conducted with each participant by three researchers, two of whom were graduate students and the third who was the principle investigator. Each interview was audio-taped and later transcribed verbatim by a graduate student who re-read the transcripts multiple times to ensure accuracy in transcription. Interviews lasted 30 to 60 minutes. Appointments were scheduled with each participant at a location of her choice (e.g., home, school, or other convenient location). In some cases, family members were present during the interviews. Since all participants were minors, the interviewer apprised cach participant of her rights within this study and obtained written consent from a parent/guardian as well as assent from the participant. All participants were assigned pseudonyms by the research team.

\section{Interview Guide}

The data for this study were obtained as part of a larger study examining recreation participation by adolescent girls with physical disabilities. Using relevant literature and previous research, the researchers designed the original interview guide, which included questions about participation in recreation activities, perceptions of self when in recreation activities, reactions of friends and family, role models, support for participation and perceptions of disability. Specific interview questions were analyzed to answer the research questions posed in this analysis: a) What physically active recreation activities do adolescent girls with physical disabilities participate in? (Questions asked included "What do you do for fun? With whom? How did you find out about the activities? Who did you learn the activities from?), b) What social sup- 
port mechanisms are in place for girls' with disabilities introduction to and participation in formal and informal recreation participation? (How does your family react to your participation in these activities? Friends? Do you ever feel uncomfortable doing activities in front of people you don't know? Do you ever feel that if you participate in physical activities others might stare/laugh? Do you have role models? Who?), c) How do outcomes by type of participation differ? (What does normal mean to you? What have you learned from role models, women with disabilities, etc.? How do you feel when you are doing these activities?') and d) How are these outcomes influenced by social support? The researchers included appropriate prompts to facilitate the interview in the case that a respondent was unclear on a question. Only data obtained through the interviews that pertained to social support are presented here.

\section{Data Analysis}

The authors conducted qualitative analyses of the interview transcripts through the use of constant comparison technique. According to Patton (1990), constant comparison is used to "group answers...to common questions (and) analyze different perspectives on central issues" (p. 376). These categories are used to organize and reduce the data, allowing for like data to be grouped with like data and patterns to emerge (Dye, Schatz, Rosenberg, \& Coleman, 2000). In this study data were read independently multiple times by two researchers to identify themes related to social support, specifically within the context of the Pines, Aronson, and Kafry (1981) model and participation outcomes. Each reader coded her data in the margins of the interviews searching for themes related to social support and participant outcomes. Because of differences that emerged in looking at these two issues across the entire sample, data were also delineated between participants in organized and non-organized sports. Upon completion of initial categorization into themes, the readers focused on reaching agreement on their independent coding.

Trustworthiness was addressed in two primary ways. First, the researchers attempted to conduct an "interpretive read" (Mason, 2002, p. 149) by which the researchers infer meanings from the understanding and representations of the data to make sense of a social phenomena in this case, social support experienced by girls with disabilities who participate in formal versus informal sport. Second, it is important to protect against one-sided interpretations, therefore two of the researchers read and re-read the data to determine appropriate themes and code the themes (Henderson, 1991). In addition, one of the researchers was not involved in the interview process nor was she involved in the development of the research questions (Dupuis, 1999). The review of the data demonstrated high level of agreement in terms of themes, as well as meanings of responses. Whenever agreement was not initially present, a re-reading of the data was conducted to account for differing viewpoints until a consensus on the data was achieved.

\section{Findings}

The two groups in this study were comprised of young girls ranging in age from 10 years old to 18 years of age. All of the girls were able to participate in a verbal interview with no assistance. Of the 22 girls who were interviewed, 13 of them par- 
ticipated in organized sport programs developed through BlazeSports America such as basketball, track and field, and swimming. The remaining nine girls participated in only informal activity such as therapeutic horseback riding, basketball in the backyard and swimming at the local YMCA. For those girls who participated in informal activities, their participation in physical activity was exceedingly low.

There was an eclectic mix of disabilities represented within each of the groups of girls interviewed. In the group that participated in organized sport, six had spina bifida, three had cerebral palsy, two had a leg amputation and only used a wheelchair for sport, one had osteogenesis imperfecta (brittle bone disease), and one girl was classified as having unspecified limited mobility. In the group of girls who participated in informal activities, four had cerebral palsy, two had spina bifida, one had osteogenesis imperfecta (brittle bone disease), one had cerebral anoxia (lack of oxygen to the brain due to a fall into water), and one girl was classified as having limited mobility.

As aforementioned, there were some distinct differences in the activities in which the two groups of girls participated. Those who were participants in organized sport

TABLE 1

Organized Sport Participants

\begin{tabular}{|c|c|c|c|c|c|}
\hline Pseudonym & Age & Race & Disability & Mobility Aid & Organized Sport(s) \\
\hline Jan & 16 years & mixed race & $\begin{array}{l}\text { osteogenesis } \\
\text { imperfecta }\end{array}$ & wheelchair & basketball, track \& field \\
\hline Maddie & 15 years & white & spina bifida & wheelchair & basketball, swimming \\
\hline Savannah & 16 years & white & spina bifida & wheelchair & basketball \\
\hline Christine & 10 years & white & spina bifida & wheelchair & basketball \\
\hline Janie & 10 years & white & spina bifida & wheelchair & basketball \\
\hline Dani & 13 years & white & spina bifida & wheelchair & basketball \\
\hline Morgan & 18 years & white & spina bifida & wheelchair & basketball, track \& field \\
\hline Leticia & 18 years & Hispanic & cerebral palsy & $\begin{array}{l}\text { wheelchair } \\
\text { (for activity) }\end{array}$ & basketball \\
\hline Hailey & 10 years & white & amputee (leg) & $\begin{array}{l}\text { wheelchair } \\
\text { (for activity) }\end{array}$ & basketball, swimming \\
\hline Lindsay & 14 years & $\begin{array}{l}\text { African } \\
\text { American }\end{array}$ & cerebral palsy & wheelchair & basketball, track \& field \\
\hline Brianna & 10 years & white & amputee (leg) & $\begin{array}{l}\text { wheelchair } \\
\text { (for activity) }\end{array}$ & basketball, swimming \\
\hline Kylie & 14 years & white & limited mobility & wheelchair & basketball, swimming \\
\hline Hannah & 16 years & white & cerebral palsy & wheelchair & basketball, track \& field \\
\hline
\end{tabular}


were involved in three main sports - basketball, track and field, and swimming. Those girls who were involved in informal activities took part in a variety of activities including therapeutic horseback riding, basketball in the backyard, swimming at the local pool, bowling, biking, bocce ball, and walking the dog, among others. See Tables 1 and 2 for a further description of the participants with pseudonyms.

\section{Themes}

Through comparing the interviews conducted with those girls who were affiliated with an organized wheelchair sport program and those girls who were not, five themes related to sport participation emerged that were all interrelated through the multidimensional concept of social support. Utilizing this typology in the analysis of the themes, it became apparent that social support was experienced in different ways by the two groups of girls. According to Dupuis (1999), it is no longer acceptable to only present commonalities" (p.55). Therefore, the five major themes that emerged from the collection of interviews: (1) role models, (2) reactions, (3) similarity to others,

\section{TABLE 2}

Organized Sport Non-Participants

\begin{tabular}{|c|c|c|c|c|c|}
\hline Pseudonym & Age & Race & Disability & Mobility Aid & Activities \\
\hline Marsha & 13 years & white & cerebral palsy & walker & $\begin{array}{l}\text { therap. horseback } \\
\text { riding, go outside } \\
\text { with friends }\end{array}$ \\
\hline Brandi & 16 years & white & cerebral palsy & $\begin{array}{l}\text { electric } \\
\text { wheelchair }\end{array}$ & $\begin{array}{l}\text { basketball } \\
\text { therap. horseback } \\
\text { riding }\end{array}$ \\
\hline Michelle & 10 years & white & limited mobility & wheelchair & $\begin{array}{l}\text { karate, baseball, bike, } \\
\text { trampoline, bocce ball }\end{array}$ \\
\hline Ginny & 14 years & white & spina bifida & $\begin{array}{l}\text { electric } \\
\text { wheelchair }\end{array}$ & swimming, bowling \\
\hline Cindy & 16 years & white & $\begin{array}{l}\text { osteogenesis } \\
\text { imperfecta }\end{array}$ & $\begin{array}{l}\text { electric } \\
\text { wheelchair }\end{array}$ & walk dogs, bowling \\
\hline Mary Ann & 14 years & white & spina bifida & walker & $\begin{array}{l}\text { basketball, fencing, } \\
\text { swimming }\end{array}$ \\
\hline Molly & 15 years & white & cerebral palsy & wheelchair & swimming \\
\hline Jaime & 16 years & white & cerebral palsy & wheelchair & $\begin{array}{l}\text { throwing balls } \\
\text { therap. horseback } \\
\text { riding }\end{array}$ \\
\hline Tracey & 12 years & white & cerebral anoxia & wheelchair & kickball \\
\hline
\end{tabular}


(4) benefits associated with participation, and (5) goals, are presented with a focus on the differences between the two groups of girls.

Role Models. There was a clear difference between the groups of girls (formal and informal participants) in regard to the presence of active role models in their lives. Informal participants could not name someone specific they felt was a role model. For instance, when Marsha was asked if she had any role models in physical activities she replied, "Not really." When Ginny was asked if there were any role models she had that she learned good lessons from she said, "Um...no, not really." It appears that these girls are missing out specifically on the social support that is often provided by role models within a sporting context.

Many of the girls who participated in organized sport commented on their role models and the social support they provided. For example, Morgan, when talking about the sports camp she attended, referred to one of the older adults who also had a disability as her role model. She stated,

they're big role models for, uh younger people, you know, the older people with disabilities that not necessarily have had their disability from birth but you know they're dealing with it right now... My basketball coach is in a wheelchair... and she's in her forties. She's active. She's actually the one that really got me interested in it. I mean, yeah, I know I said that my friends were the ones that got me to go out for the team, but she's the one that really got me loving the sport you know.

Also, those girls who participated in organized sport clearly had role models who provided support. Dani reported that her sister and her grandmother were role models that she looked up to "because she (sister) has always been there supporting me and my grandmother because she always cheers me on and makes me feel like she's just proud of me."

Kylie, who also participated in organized sport, talked about a role model she had who was another woman with a disability who had participated at a high level of organized sport. This role model motivated her to work harder, ultimately achieving personal growth. "Like my friend Ashley, she just went to the Paralympics. Like I sort of look up to her, and try to beat her whenever I swim, even though it never works."

Additionally, girls who participated in organized sport seemed to have an increased opportunity to meet and identify with other athletes with disabilities. Maddie talked about her role model (a female with a disability),

she's [been] my basketball coach for two years and she's been basically like my role model for basketball, like, she was my very first coach, very first person that ever taught me how to play basketball and so she's actually the person that, she's the coach at Alabama right now.

Lindsay talked about her favorite athlete who participated in wheelchair track and field at the University of Illinois as one of her role models who provided sport specific support. When asked why she would consider this athlete a role model she stated, "well number one she's a girl.... and she just inspires me." Lindsay also indicated that her role model encourages and supports her to achieve more and do better in sports. She stated, "I've learned everything from her. Basically, go out there, do your best, and it doesn't matter if you win or lose just as long as you finish."

Reactions to Informal and Formal Sport Participation. Both groups of girls experienced diverse reactions to their participation in sport from their family, friends, coaches, and 
peers. While many of the formal participants felt a great deal of sport related support, a primary focus for informal participants was their disabilities, rather than any type of sport participation.

It was evident that both groups of girls received support from their friends and/or peers, albeit, again, only outside the context of sport for informal participants. For example, Jaime, referring to a peer at church who also has a disability, stated, "I was nervous about high school. It was kind of nice to know that I have somebody that I can talk to, that relates to how I feel." Whereas, those girls who were involved in organized sport received support from their friends at school that directly related to their accomplishments in sport. For example, Morgan stated in reference to her friends, "the time I came back from Nationals, they all wanted to hear about it so it was nice."

The informal participants' support pertained more to their disability rather than any achievement. Jaime stated, "My friends tell me that it's not my fault that I have cerebral palsy. So it's kind of good to get their point of views and understand that I am not the only one that has a disability like this." However, those girls who were involved in organized sport received shared support from their teammates in the context of sport participation and competition. Leticia, when asked why she liked playing organized sport, stated,

'cause there's a lot of different people, I think, outside of my comfort zone and there's a lot of people that can relate to you with your disabilities and stuff like that, so you kind of get on a whole new level when you compete because you have people who understand you better.

The reactions received by those girls who do not participate in organized sport appear to be slightly different from participants. Marsha described her friends' reactions to situations she faces as overprotective. She stated, "well, they stick up for me most of the time, and I stick up for them. When people are bugging me they get on their case." Jaime's idea of emotional support also related to protecting those who are disabled from emotional hurt, "If any kids that don't have disabilities pick on them, I think that it's nice for them to and important for them to know that they have friends that they can count on and talk to if they have any problems."

On the other hand, while Jan's parents were initially afraid "(she) might break" if she participated in wheelchair sport, her ongoing participation and success have helped them realize and acknowledge her seemingly limitless potential. It was clear that the girls who participated in organized sport truly felt supported in their sport participation. Morgan also indicated her family's support stating, "Oh they love it. They come out for competitions all the time, you know. I mean it's not just one parent coming with me it's a, you load up the whole van, my whole family comes. So it's like a family thing." Christine also provided an example of emotional support when she commented on her family stating, "I feel that they really want me to do this stuff, and they are going to help me along the way."

The informal participants' comments regarding their participation in non organized activity often reflected an uncertainty in the degree of support their friends were willing to provide. A number of the girls indicated that their friends would likely be skeptical as to whether they could successfully participate in sport. For example, Ginny talked about how her friends might respond if they found out that she participated in any type of physical activity stating, "they would possibly react that they couldn't think I could do this and stuff." 
On the contrary, the girls who participated in organized sport undoubtedly received support from their family and friends. Leticia indicated that her family pushes her to continue her participation in sport due to the beneficial outcomes,

he [dad] loves it because he thinks that it will help you with your self-esteem and stuff like that and it's something positive, it's not anything negative so he's really happy about it. My mom she likes it because it's something that I'm doing different with myself instead of sitting at the house and doing nothing all day.

Maddie also talked about how her family reacted to her playing organized sport, "I practice everyday at Stingrays and stuff like that. My mom is always trying to get me to practice everyday and so they really encourage me to get in sports." Lindsay talked about the encouragement that her friends provide her referring to her participation in sports, "my friends think it's great.... They're like 'oh really, that's great'.... They encourage you so.... They're like 'great, you can do this, I know you can do this."'

Reactions to informal participation reflected that sport-specific support is simply not as evident in the lives of informal participants. Michelle, when asked how her family reacted to her doing things like karate and bike riding, stated, "they are all right with it. Like they don't really care or anything. Like they come and watch and everything and they care if I am having fun but they don't really care if I am doing it or not." Whereas, the girls who participate in organized sport definitely receive encouragement and support tied to their participation in sport. The girls commented on how amazed their friends were that they could participate in sport as successfully as they did. Leticia talked about her friends' reactions to her ability to play wheelchair basketball,

They think it's cool because they can't grasp the concept of how you can play basketball in your chair and go up and down the court so much so they think it's pretty cool. I've had a couple of my friends come and watch me play and they're just amazed and they...came back to try to help out as much as they can.

Morgan commented, "you know it's not important to me to get glory for sport and everything, but you know at the same time it's nice when somebody recognizes competitions and things."

The formal participants found that their friends, family, and other significant people in their lives provided social support that served as a challenge to excel in sport, although it is important to note that the challenge is more self-generated by the participant often in response to an assumption by others that they cannot perform in a sport. Morgan, who participated in organized sport, discussed how her friends' skepticism empowered her to do better and achieve more in her sport. When she was asked who did not think she could participate in sports she replied

just like my friends and everything, they were like well if you give up now you're never gonna be able to do it. And you know they were trying to encourage me, but they were really discouraging at the same time. So, I was like, you know what, I'm gonna prove you wrong, I'm gonna do it, you know, and I got a gold medal my first competition.

Similarity to Others. It became obvious that informal participants did not think of themselves as necessarily like other girls without disabilities, but defined themselves more by their disabilities. Therefore, their interactions reflected camaraderie amongst those who have a disability rather than with able-bodied girls. These girls defined their similarity to others more by their disabilities rather than their abilities in sport or any other form of physical activity. Brandi commented on how she felt most nor- 
mal around a peer who also had a disability stating, "I feel normal because he sort of accepts me because he had a stroke a couple of years ago and we talk about the difficulties of being disabled and having disabilities." Jaime, when asked if she thought she was the same as able-bodied children, responded by stating, "I think that [it's] important for any kid with a disability to know that no matter what kind of disability they have, they are not the only ones going through this," thus aligning herself with other youth with disabilities.

Many of the girls who participated in organized sport not only viewed themselves as normal but also similar to many of their peers and family members without disabilities. These feelings were reciprocated thus resulting in greater perceptions of support. Maddie commented, "the people that play sports with me think I'm normal and I think that they're normal and there's no difference." Savannah, when asked if she saw herself as normal, commented, "I don't think that there is anything wrong with me." When asked further if her parents treated her any differently than her non-disabled sibling she claimed they did not. Janie, who plays basketball and other wheelchair sports, felt that the culture of sport, for athletes with and without disabilities, allows girls with disabilities the opportunity for extended social support. Janie identifies with feeling normal because she plays sports and "a lot of kids at my school are like, in baseball, and football and all that stuff."

Benefits Associated with Participation. It was obvious that both groups of girls had friends who provided support by participating in activities with them in some way or another; however, there was a distinct difference between the groups pertaining to the benefits obtained from physical activities. The informal participants reported that they received benefits from informal physical activities that were more related to their therapy rather than recreation. Jaime reflected on how her therapeutic horseback riding made her feel. She stated, "I felt really good about myself. I was able to be around kids and to know that I was not the only one going through this." For informal participants, therapy is central to their physical activity. Tracey discussed her resistance to her therapy; however, she also commented on how social support from her friends encourages her to be compliant with her exercise program. When referring to whether she liked her exercises she stated, 'I don't really know about that part, 'cause I don't ever do them. The reason I don't do them is because my best friend's not at my house to do them with me. Cause I like to do exercises with somebody." The social implications are clear.

Recognizing how important the benefits associated with participation in sport are, it is equally as important to identify the lack of support in this area for those girls who do not participate in organized sport. Brandi, who uses a motorized wheelchair, experienced a barrier to her participation. She reported, "I've done basketball in lunch activity and I wanted to get out on the team but, they won't let people with motorized chairs play."

As a formal sport participant, Morgan stated that her participation allowed her to "just hang out with a lot of people like me.... It's just inspiring to see people that have done this for years and years when you're just starting out." Janie referenced the benefits that she attained through participation, "I like to keep myself active so I can keep myself in good health and all that stuff. But it's also like fun, and it's fun because all my friends do it." 
In addition, only those girls who participated in organized sport received social support that facilitated both emotional and sport skill growth which can be linked to the benefits that they felt they gained from participation. Maddie commented, "well it's just lots of fun because like, I feel happy because like with people that are my age or that I can get along with and it's just a lot of fun to play sports, it keeps me in shape." While Brianna's mom is supportive, Brianna has conflicting feelings surrounding the sport-specific challenges her mother gives her. She stated,

my mom wants me to get like really into it and I think I don't want to. I wanna be a good sport, but I don't want to go pro at a sport. You know I just wanna stay in shape, have fun, be strong, but I don't wanna... She's like 'hey if you don't do this you can't get better.' I don't really want to get better. I just want to stay at this level. This level is good.

Goals. The goals for both groups of girls appear to be remarkably different. For the girls who did not participate in organized sport their goals were more oriented to the present and often focused on increased functioning. Additionally, their goals tended to be more therapeutic oriented rather than based on achievement in sport. While not related to formal sport participation, therapists who some of them have worked with appear to challenge the informal participants to succeed at their physical therapy, a challenge that is somewhat similar to that experienced by formal participants. A common goal of informal participants, as exemplified by Tracey was, "I want to get out of this wheelchair and learn to walk again."

For the girls who participate in organized sport most often their goals were future oriented and included attending college and attaining a higher level of competition such as the Paralympics or varsity athletics. The sports organization and/or the people they encounter often provide social support for these goals through sport-specific support. For example, Kylie stated, "just doing regular swimming with my able-bodied team, umm, it's fun there, but with Blaze I have done so much more better, and I hope to go to the Paralympics soon, too." This finding is consistent with Blauwet's (2005) assertion that people who participate in disability sport often see potential for success in all areas of life.

\section{Discussion}

The study was designed to examine the differences in levels of social support experienced by girls who participate in formal versus informal disability sport. Overall, the findings revealed that there were distinct differences in levels of social support, and thus experiences, enjoyed by the two groups of girls.

An examination of the findings in light of Pines and Aronson's (1988) model of social support (for a review, see p. 189) illuminates the fact that formal sport participants experienced high and varied levels of social support. The outcomes that resulted from this participation and support included access to role models, perceptions of similarity to others, activity benefits including physical fitness and fun, positive reactions including encouragement, and goal development. While the girls who were informal participants experienced some social support as well, it was often limited to their disability, not their role as an athlete.

The first area where this was apparent was within the context of relationships with role models. Those girls who participated in organized sport had much greater 
interaction with role models who were able to provide emotional support, emotional challenge support, shared social reality support, technical appreciation support, and technical challenge support. In fact, none of the informal participants could even name a role model. For example, Morgan's statement about her basketball coach who is also in a wheelchair illustrates an instance of shared reality support in that she felt her coach shared her understanding of the world. Furthermore, the relationships with the role models often provided occasion for both being "pushed" or challenged as an athlete as well as gaining a sense that another person appreciated and supported their efforts and accomplishments in a sport. Therefore, these relationships provided the athletes with both technical appreciation support and technical challenge support.

Within the theme "reactions to informal and formal sport participation," there were numerous instances of social support identified, albeit with differences between formal and informal participants. The reactions from family, friends, coaches, and peers influenced perceptions of listening support, shared social reality support, emotional support, emotional challenge support, technical appreciation support, and technical challenge support. While both groups experienced a variety of social support in this context, the primary difference was that reactions from significant others to informal participants were focused on their disabilities while reactions to formal participants centered on sport participation. Leticia provided a good example of shared social reality when she discussed her enjoyment of participating in organized sport because participants understand one another. On the other hand, the emotional support felt by Marsha, an informal participant, was centered on her disability in that she indicated her friends stuck up for her when she is picked on because of her disability. Both groups experienced a variety of support through reactions from significant others, although as one might expect, technical appreciation support and technical challenge support were rarely experienced by the informal participants who likely did not come into contact with anyone who had the ability to provide these types of support. The lack of these types of support would likely limit the pursuit of greater sport participation.

As mentioned earlier, the formal participants were more likely to see themselves as similar to girls without disabilities. While both groups experienced shared social reality support, the similarity to others felt by informal participants was defined through the presence of a disability, not the participation in sport as it was for formal participants. Janie summed up the perceptions of similarity felt by many of the formal participants when she equated her own sport participation to that of her classmates - they were all athletes.

The benefits that participation in formal activities provided was evident through the different types of support gained in that context including emotional support, emotional challenge support, and technical challenge support. However, only the girls who participated in organized sport experienced benefits tied to emotional challenge support and technical challenge support including enjoyment of participating with other girls their age, physical fitness, and challenges by parents to advance and achieve success such as those identified by Brianna.

Finally, while both groups of girls experienced technical challenge support that led to the formation of goals, the support was again a dichotomy of disability-centered and sport-centered. For instance, Tracey, an informal participant, had a goal tied to challenges her physical therapist had set - walking. On the other hand, formal participant 
Kylie's goal was sport related - going to the Paralympics. The formal participants' goals also tended to be more future oriented.

Figure 1 illustrates a model of the findings from the study. As participation in sport by girls with physical disabilities is more organized and their social support is stronger, and more hetereogeneous, participation has a greater chance of resulting in positive developmental outcomes including long-term goals, interaction with role models, perceptions of similarity to others, a variety of goals such as good health tied to sport, and positive reactions to the girls' abilities. Limited social support, which was observed with the girls who participated in informal activity, tended to be tied to outcomes related to therapy and other disability related outcomes. The dashed lines on the model reflect the barriers that were found that are representative of those often faced by girls with disabilities in relation to their participation levels. Lower levels of barriers including lack of peers with which to participate, lack of knowledge about opportunities, and fear of injury tend to be barriers that are directly tied to the presence of a disability and thus often prevent even lower levels of participation and thus impede positive development. If these barriers are overcome and participation increases, higher order barriers can still erect challenges. However, these barriers tend to be similar to barriers experienced by able-bodied athletes as well including costs associated with travel for higher levels of competition and time constraints due to competing interests.

While this study examined social support in the context of sport, a number of researchers do not differentiate the socialization process of leisure from sport (and recreation as well as physical activity) and refer to them interchangeably (Brasile \& Hedrick, 1991; Kelly, 1980; Page, O’Connor, \& Peterson, 2001). Therefore, it would be appropriate to apply the findings to the context of leisure in general thus furthering the examination of leisure benefits and barriers for girls with disabilities. It is likely

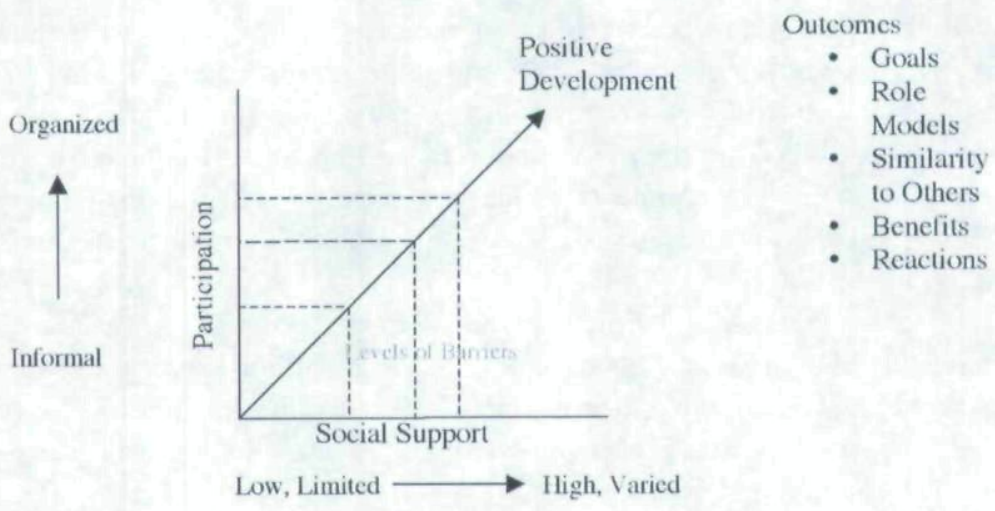

Figure 1. Model of Disability Sport Participation 
that the same sorts of outcomes related to social support found in this study would be relevant to other formalized physical leisure activities such as dance, fitness activities, and outdoor pursuits such as kayaking and rock climbing.

Social support is of extreme value to adolescent girls. If organized sport as a unique context can provide the opportunity for girls to experience increased social support in general, then increasing these opportunities should be of manifest importance. However, as Martin and Mushett (1996) observed, it is important "to match the type of support with what is needed" (p. 74). It appears from the data that when each girl's family, friends, and peers provide appropriate support according to Pines and Aronson's (1981) model, that girls with disabilities can reap multifaceted benefits through wheelchair sport participation. Formal sport in particular seems to provide a conducive setting for the type of social support that can facilitate outcomes such as physical fitness, long-term goal setting, and identity development.

The girls who participated in informal sport revealed that, unlike participants in organized disability sport, they had limited access to physically active role models and thus the social support they can provide for participation. For any athlete, disabled or not, a role model can be very motivating and provide much needed support that can carry over into other facets of life. It is important for an individual with a physical disability to observe someone with a similar disability achieve success in physical activity, thus providing proof that physical activity is possible and promoting attitudes that they too can be successful in sports and other forms of leisure (Kersten, Gabriele, \& Richard, 2006).

Another distinct difference between the two groups of girls is in the types of physical activities in which they engage and the inherent social support necessary for and embedded within participation. Many of those who did not participate in organized sport attributed most of their physical activity to what they identified as physical therapy rather than "sport" and the social support provided in those settings focused on their disabilities. Whereas, those girls who participated in organized sport had a larger social support base both in and outside the competitive arena. French and Hainsworth (2001) alluded to the fact that there are inherent benefits to active recreation compared to therapy. Sylvester (1996) discussed the significant difference between activities done for the sake of leisure versus those prescribed by others such as therapy. He made the distinction that an activity that is prescribed for the purpose of treating an ailment is considered a therapy, which neglects a person's self-determination and infringes on her autonomy. On the other hand, an activity that is considered leisure implies that the individual has the freedom to choose the activity and the anticipated results as determined by the individual and not another person, therefore fostering one's selfdetermination and autonomy - two additional benefits of disability sports.

In a related vein, girls who participated in the sport program also had a greater sense of comfort and normality than those who did not, in part due to the social support tied to their participation. While the primary goal of wheelchair sports is not normality, but empowerment, it would be foolish to think that a sense of normality is not important to teenage girls. In a study of able-bodied adolescent girls, James (1999) found that many avoided leisure spaces such as swimming pools and basketball courts due to the concern that they would be ridiculed or get hurt. However, the girls participating in disability sport countered this notion by emphasizing their comfort in sport 
and the fact that oftentimes they feel most "normal" when they are playing sports. In addition, not only were they unconcerned about being ridiculed, but they also had not experienced ridicule. In fact, one girl indicated that the support she received from friends reflected their concern (rather than her own) about her being teased.

Finally, social support for therapy versus social support for sport participation can have different implications. Therapy is typically used to maintain current functioning and prevent further loss of physical ability while sport is more about pushing oneself and achieving new physical goals beyond retaining or attaining a previous status quo (Blinde \& McCalliser, 1999). The researchers found that sport participants in this study had sport related goals and related social support for those goals from role models and other avenues as well as social support that drove them to set additional long-term goals irrespective of their disabilities. Informal participants seemed more concerned about participation as a way to pass time with little future direction; their goals were more immediate and goals tied to the future and possibilities such as college did not emerge.

\section{Limitations}

As with all research, there were limitations inherent in this study. First, although snowball sampling technique was employed, the researchers still had difficulty in obtaining participants for the study. As a result, the variance of participant backgrounds and disabilities was somewhat limited. Related to this, most of the participants used a wheelchair or other ambulatory device in everyday life and all did for sport participation. Thus, girls with physical disabilities that are less noticeable are absent from this study. Finally, in several cases, a parent was present for the interview. It is unclear to what extent their presence may have influenced the responses of the participants.

\section{Future Research}

Recommendations for research include the consideration of alternate methodologies as well as additional content. First, a quantitative test of the social support model for both groups of girls would give a more complete picture of the outcomes from participation in wheelchair sport for girls with physical disabilities. Second, focus groups with non-participants inquiring about the facilitation of social support through recreation providers may help increase opportunities for support both in informal and formal sport and recreation opportunities. Recognizing that the development of and implications for social support can differ by sport/activity, it would be beneficial to study different sports, especially team versus individual pursuits. Finally, an in-depth study of the benefits of non-sport physical activity may provide for a greater knowledge base on more relevant or accessible opportunities for physical activity to contribute to greater levels of social support or vice versa.

\section{Implications/Recommendations}

This research study reveals practical implications for the leisure service ficld. One of the most obvious implications is that organized sport provides a venue that fosters social support for girls with disabilities and in return social support benefits the girls' positive development as outlined by the study's themes. Thus, practitioners need to 
recognize the importance of gaining programmatic experience and even expertise in working to adapt existing programs or develop new programs that would provide organized opportunities for girls with disabilities. This study found that role models could be instrumental in this process as well. Therefore, the programmer may also want to consider networking with potential role models to ensure access to successful athletes with disabilities for the girls. Leisure service providers can have direct access to young girls with disabilities if they provide encouragement for participation through facilitation techniques such as appropriate marketing, advocacy for the girls both in recreation and well as in the community in general, the development of skill workshops to introduce girls to sport, and a welcoming environment. This study outlines the unique importance of formal sport participation, particularly within the context of its ties to social support. It is the responsibility of practitioners to encourage this participation in order to reach this population and thus assist them in obtaining the benefits of organized sport that have been reported here.

In conclusion, it appears that social support manifests itself in a much different manner for girls with disabilities who compete in organized sport when compared to informal participants. Within the context of the social support model differences in outcomes from participation in formal versus informal sport participation indicated that girls with disabilities likely both felt greater support to initially engage in sport as well as support to continue their participation. This participation also facilitated the development of goals related to competitive sport including higher-level functioning and competition as well as an increased sense of ability, self-esteem, and enjoyment from this participation. It is reasonable to assume that these outcomes will continue to have a positive effect on the lives of girls with disabilities who participate in sport programs designed to meet the unique challenges of their disability status.

\section{References}

Anderson, D. M., Bedini, L. A., \& Moreland, L. (2005). Getting ALL girls into the game: Physically active recreation for girls with disabilities. Journal of Park and Recreation Administration, 23(4), 78-103.

Appleton, P. L., Minchom, P. E., Ellis, N. C., Elliott, C. E., Boll, V., \& Jones, P. (1994). The selfconcept of young people with spina bifida: A population based study. Developmental Medicine and Child Neurology, 36, 198-215.

Ashton-Shaeffer, C., Gibson, H., Autry, C. E., \& Hanson, C. S. (2001). Meaning of sport to adults with physical disabilities: A disability sport camp experience. Sociology of Sport fournal, 18, 95-114.

Ashton-Shaeffer, C., Gibson, H., Holt, M., \& Willming, C. (2001). Women's resistance and empowerment through wheelchair sports. World Leisure fournal, 43(4), 11-21.

Benson, S. (1997). The body, health, and eating disorders. In K. Woodward (Ed.), Identity and difference (pp. 121-181). London: Sage.

Blauwet, C. (2005). Promoting the health and human rights of individuals with a disability through the Paralympic movement. Retrieved November 12, 2006, from http://www.paralympic.org/development.

Blinde, E. M., \& McCallister, S. G. (1999). Women, disability, and sport and physical activity: The intersection of gender and disability dynamics. Research Quarterly for Exercise and Sport, 70(3), 303-312. 
Blinde, E. M., \& McClung, L. (1997). Enhancing the physical and social self through recreational activity: Account of individuals with physical disabilities. Adapted Physical Activity Quarterly, 14, 327-344.

Blinde, E. M., Taub, D. E., \& Han, L. (1994). Sport as a site for women's group and societal empowerment: Perspectives from the college athlete. Sociology of Sport Journal, 11, 51-59.

Brighton Declaration on Women and Sport. (1994). Retrieved November 12, 2006 from www.sportsbiz.bz/womensportinternational/conferences/brighton_declaration.htm.

Brittain, I. (2004). The role of schools in constructing self-perceptions of sport and physical education in relation to people with disabilities. Sporl, Education and Society, 9(1), 75-94.

Campbell, E. (1995). Psychological well-being of participants in wheelchair sports: Comparison of individuals with congenital and acquired disabilities. Perceptual and Motor Skills, 81, 563568.

Collins, K., \& Barber, H. (2005). Female athletes' perceptions of parental influences. Journal of Sporl Behavior, 28(4), 295-314.

Dahms, B. Doll, \& H. Selzam (Eds.), Adapled physical activity: An interdisciplinary approach (pp. 43-51). New York: Springer-Verlag.

Deegan, M. J. (1985). Multiple minority groups: A case study of physically disabled women. In M. J. Deegan \& N. A. Brooks (Eds.), Women and disability: The double handicap (pp. 37-55). New Brunswick: Transaction Books.

DePauw, K. P. (1997). The (In)Visibility of disAbility: Cultural contexts and "sporting bodies." Quesl, 49, 416-430.

DePauw, K. P. (1999). Girls and women with disabilities in sport. The Journal of Physical Education, Recreation, and Dance, 70(4), 50-54.

DePauw, K. P., \& Gavron, S. J. (2005). Disability sport. Champaign, IL: Human Kinetics.

Doubt, L., \& McColl, M. A. (2003). A secondary guy: Physically disabled teenagers in secondary schools. Canadian Journal of Occupational Therapy, 70(3) 139-151.

DuBois, D. L., Felner, R. D., Brand, S., Adan, A. M., \& Evans, E. G. (1992). A prospective Study of life stress, social support, and adaptation in early adolescence. Child Development, 63(3), 542-557.

Dupuis, S. (1999). Naked truths: Towards a reflexive methodology of leisure research. Leisure Sciences, 21, 43-64.

Dunn, J. C. (2000). Goal orientations, perception of the motivational climate and perceived competence of children with movement difficulties. Adapted Physical Activily Quarterly, 17, 1-19.

Dye, J. F., Schatz, I. M., Rosenberg, B. A., \& Coleman, S. T. (2000, January). Constant comparison method: A kaleidoscope of data. The Qualitative Report, 4(1/2). Retrieved April 5, 2007, from http://www.nova.edu/ssss/QR/QR4-1/dye.html.

Eccles, J. S., Barber, B. L., Stone, M., \& Hunt, J. (2003). Extracurricular activities and adolescent development. Journal of Social Issues, 59(4), 865-890.

Fitness Canada (n.d.) Physical activily and women with disabilities: A national study. Ottawa, ON.

French, D., \& Hainsworth, J. (2001). "There aren't any buses and the swimming pool is always cold!": Obstacles and opportunities in the provision of sport for disabled people. Managing Leisure, 6, 35-49.

Fries, J. (1998). Reducing cumulative lifetime disability: The compression of morbidity. British Journal of Sports Medicine, 32(3), 193.

Greenwood, C. M., Dzewaltowski, D. A., \& French, R. (1990). Self-effiacy and psychological well-being of wheelchair tennis participants and wheelchair non-tennis participants. Adapted Physical Activity Quarterly, 7, 12-21. 
Guthrie, S. R., \& Castelnuovo, S. (2001). Disability management among women with physical impairments: The contribution of physical activity. Sociology of Sport Journal, 18, 5-20.

Hardin, M. (2003). Marketing the acceptably athletic image: Wheelchair athletes, sport-related advertising and capitalist hegemony. Disability Studies Quarterly, 23(1), 108-125.

Hardin, B., Hardin, M., Lynn, S., \& Walsdorf, K. (2001). Missing in action? Images of disability in Sports Illustrated for Kids. Disability Studies Quarterly, 21(2), 21-32.

Hargreaves, J. (1987). The body, sport, and power relations. In J. Horne, D. Jary, \& A. Tomlinson. Sport, leisure, and social relations (pp. 139-159). New York: Routledge \& Keegan Paul.

Hargreaves, J. (2000). Heroines of sport. The politics of difference and identity. New York: Routledge.

Hedrick, B. N. (1986). Wheelchair sport as a mechanism for altering the perceptions of the nondisabled regarding their disabled peers. Therapeutic Recreation Journal, 20(4), 72-84.

Hedrick, B. N., Morse, M. I., \& Figoni, S. F. (1988). Training practices of elite wheelchair roadracers. Adapted Physical Activity Quarterly, 5, 140-153.

Henderson, K. A. (1991). Dimensions of choice: A qualitative approach to recreation, parks, and leisure research. State College, PA: Venture Publishing.

Henderson, K. A., \& Bedini, L. A. (1995). "I have a soul that dances like Tina Turner, but my body can't": Physical activity and women with mobility impairments. Research Quarterly for Exercise and Sport, 66(2), 151-162.

Henderson, K. A., Bedini, L. A., \& Bialeschki, D. (1993). Feminism and the client-therapist relationship: Implications for therapeutic recreation. Therapeutic Recreation Journal, 27(1), 33-43.

Hutzler, Y. (1990). The concept of empowerment in rehabilitative sports. In G. Doll-Tepper, C. Dahms, B.Doll, and H. Selzam (Eds.) Adapted Physical Activity; An Interdisciplinary Approach (pp. 43-51). New York: Springer-Verlag.

Hutzler, Y., Fliess, O., Chacham, A., \& Van den Anweele, Y. (2002). Perspectives of children with physical disabilities on inclusion and empowerment: Supporting and limiting factors. Adapled Physical Activity Quarlerly, 19(3), 300-318.

James, A. (1998). The conceptual development of recreational therapy. In F. Brasile, T. K. Skalko, \& J. Burlingame (Eds.), Perspectives in recreational therapy: Issues of a dynamic profession (pp. 7-38). Enumclaw, WA: Idyll Arbor Pub.

James, K. (1999). "I feel really embarrassed in front of the guys!": Adolescent girls and informal school basketball. ACHPER Healthy Lifestyles Journal, 46(4), 11-16.

Jones, D. B. (2003). "Denied from a lot of places": Barriers to participation in community recreation programs encountered by children with disabilities in Maine: Perspectives of parents. Leisure/Loisir 28(1/2), 49-69.

Jones-Palm, D., \& Palm, J. (2004). Physical activity and its impact on health behaviour among youth. Retrieved November 20, 2006, from the International Council of Sport Science and Physical Education Web site: http://www.org/portal/icsspe.download/PhysicalActivity.pdf.

Kenyon, G., \& McPherson, B. (1981). Becoming involved in physical activity and sport: A process of socialization. In J. W. Loy, G. S. Kenyon, \& B. D. McPherson (Eds.), Sporl, culture, and society: A reader on the sociology of sport (pp. 217-237). Philadelphia: Lea \& Febiger.

King, G., Law, M., King, S., Rosenbaum, P., Kertoy, M. K., \& Young, N. L. (2003). A conceptual model of the factors affecting the recreation and leisure participation of children with disabilities. Physical and Occupational Therapy in Pediatrics, 23(1), 63-90.

King, G. A., Shultz, I. Z., Steel, K., Gilpin, M., \& Cathers, T. (1993). Self-evaluation and selfconcept of adolescents with physical disabilities. American Journal of Occupational Therapy, 47, $132-140$. 
Kolkka, T., \& Williams, T. (1997). Gender and disability sport participation: Setting a sociological research agenda. Adapted Physical Activity Quarterly, 14(1), 8-23.

Kristen, L., Patriksson, G., \& Fridlund, B. (2002). Conceptions of children and adolescents with physical disabilities about their participation in a sports programme. European Physical Education Review, 8(2), 139-156.

Kristen, L., Patriksson, G., \& Fridlund, B. (2003). Parents' conceptions of the influence of participation in a sport's programme on their children and adolescents with physical disabilities. European Physical Education Review, 8(2), 139-156.

Martin, J.J. (1999). Predictors of social physique anxiety in adolescent swimmers with physical disabilities. Adapted Physical Activity Quarterly, 16, 75-85.

Martin, J. J. (2006). Psychosocial aspects of youth disability sport. Adapted Physical Activity Quarterly, $23,65-77$.

Martin, J.J., \& Mushett, C. A. (1996). Social support mechanisms among athletes with disabilities. Adapled Physical Activity Quarterly, 13(1), 74-83.

Mason, J. (2002). Qualitative researching. ( $2^{\text {ud }}$ ed.). London: Sage.

Mikosza, J. M., \& Phillips, M. G. (1999). Gender, sport and the body politic. International Review for the Sociology of Sport, 32(1), 5-16.

Ninot, G., Bilard, J., \& Delignieves, D. (2005). Effects of integrated or segregated sport participation on the physical self for adolescents with intellectual disabilities. Journal of Intellectual Disability Research, 49(9), 682-689.

Page, S. J., O’Connor, E., \& Peterson, K. (2001). Leaving the disability ghetto: A qualitative study of factors underlying achievement motivation among athletes with disabilities. Journal of Sport and Social Issues, 25, 40-55.

Patton, M. Q. (1990). Qualitative evaluation and research methods ( $2^{\text {nd }}$ ed.). Newbury Park, CA: Sage. Pensgaard, A. M., \& Sorensen, M. (2002). Empowerment through the sport context: A model to guide research for individuals with disabilities. Adapted Physical Activity Quarlerly, 19(1), 48-68.

Pines, A. M., \& Aronson, E. (1988). Career burnout. New York: Free Press.

Pines, A. M., Aronson, E., \& Kafry, D. (1981). Burnout. New York: Free Press.

Reid, G., \& Prupas, A. (1998). A documentary analysis of research priorities in disability sport. Adapled Physical Activity Quarterly, 15, 168-178.

Rosenfeld, L. B., Richman, J. M., \& Hardy, C. J. (1989). Examining social support and networks among athletes: Description and relationship to stress. The Sport Psychology 3, 23-33.

Ruddell, J. L., \& Shinew, K. J. (2006). The socialization process for women with disabilities: The impact of agents and agencies in the introduction to an elite sport. Journal of Leisure Research, 38(3), 421-444.

Sherrill, C., Hinson, M., Gench, B., Kennedy, S. O., \& Lou, L. (1990). Self-concepts of disabled youth athletes. Perceptual and Motor Skills, 70, 1093-1098.

Sherrill, C., \& Rainbolt, W. J. (1986). Sociological perspectives of cerebral palsy sports. Palaestra, 2(4), 20-23, 25-26.

Shugart, H. A. (2003). She shoots, she scores: Mediated constructions of contemporary femaleathletes in coverage of the 1999 US women's soccer team. Western Journal of Communication, $67(1), 1-31$.

Simeonsson, R. J., Carlson, D., Huntington, G. S., McMillen, J. S., \& Brent, J. L. (2001). Students with disabilities: $A$ national survey of participation in school activities. Disability and Rehabilitation, 23(2), 49-63.

Solomon, A. (2000). Our bodies, ourselves. The Village Vice, 45(16), 60-68. 
Stein, J. J., \& Paciorek, M. J. (1994). Sport for all: A declaration of rights of individuals with disabilities. Physical Education, 51(4), 188-194.

Sylvester, C. (1996). Instrumental rationality and therapeutic recreation: Revisiting the issue of means and ends. In Sylvester, C. (Ed.), Philosophy of therapeutic recreation: Ideas and issues, Vol. II (pp. 92-103). Arlington, VA: National Recreation and Park Association.

Taub, D. E., \& Greer, K. R. (2000). Physical activity as a normalizing experience for schoolage children with physical disabilities: Implications for legitimation of social identity and enhancement of social ties. Journal of Sport and Social Issues, 24(4), 295-414.

Tam, S. (1998). Comparing the self-concepts of persons with and without physical disabilities. Journal of Psychology, 132(1), 78-87.

Theberge, N. (1987). Sport and women's empowerment. Women's Studies International Forum, 10(4), 387-393.

Theberge, N. (1991). Reflections on the body in the sociology of sport. Quest, 43, 123-134.

Uchino, B. N., Cacioppo, J. T., \& Kiecolt-Glaser, J. K. (1996). The relationship between social support and physiological processes: A review with emphasis on underlying mechanisms and implications for health. Psychological Bulletin, 119(3), 488-531.

Whidden, M. (1986). Socialization into sport of cerebral palsied persons. Unpublished master's thesis, Texas Woman's University, Denton, Texas.

Williams, T. (1994). Disability sport socialization and identity construction. Adapted Physical Activity Quarterly, 11, 14-31.

Wyeth, D. O. (1989). Breaking barriers and changing attitudes. Journal of Osteopathic Sports Medicine, 3(4), 5-10. 
Copyright of Journal of Leisure Research is the property of National Recreation \& Park Association and its content may not be copied or emailed to multiple sites or posted to a listserv without the copyright holder's express written permission. However, users may print, download, or email articles for individual use. 